\title{
ROBUST ALGORITHMS FOR PREDICTIVE CONTROL UNDER UNCERTAINTY CIRCUMSTANCES OF THE MODEL FOR THE CONTROLLED OBJECT
}

\author{
ODPORNE ALGORYTMY REGULACJI \\ PREDYKCYJNEJ W WARUNKACH NIEPEWNOŚCI \\ MODELU STEROWANEGO OBIEKTU
}

\author{
Krzysztof Sztyber
}

Air Force Institute of Technology

\begin{abstract}
The paper is logically divided into three parts. In the first part the following question is considered. How a standard Model Predictive Control algorithm would perform in a case of model-process discrepancy? It turns out that this discrepancy could lead to control performance deterioration and even to instability of a predictive control system. In the sequel Uncertainty is described as model uncertainty, and then is introduced mathematical description of uncertainty as an analytical uncertainty model. The analytical uncertainty model can be directly used during predictive control algorithm design. In the third part some new ideas and solutions are proposed. First of all, to efficiently cope with negative effects of model-process mismatch the model uncertainty should be taken into account already during predictive control algorithm design. It can be done by the use of the analytical uncertainty model. According to the above solutions like: a fast model selection, dynamical switching sector, and a dual-phase approach to a predictive control algorithm design are presented.
\end{abstract}

Key words: modelling, systems of steering, arrangement of control

Streszczenie: Referat jest logicznie podzielony na trzy części. W pierwszej części rozpatrywane jest następujące pytanie: jak standardowy algorytm MPC będzie funkcjonował $\mathrm{w}$ przypadku rozbieżności między obiektem sterownia a jego modelem? Okazuje się, że rozbieżność ta może doprowadzić do pogorszenia jakości regulacji, a nawet do niestabilności predykcyjnego układu regulacji. W dalszej części, opisywana jest niepewność modelu i wprowadzony zostaje matematyczny opis niepewności jako analityczny model niepewności. Model ten może być bezpośrednio użyty podczas projektu predykcyjnego algorytmu regulacji. W części trzeciej zaproponowano pewne nowe idee i rozwiązania, które moga poprawić jakość i niezawodność predykcyjnego systemu sterowania. Przede wszystkim, żeby skutecznie radzić sobie z negatywnymi efektami rozbieżności między procesem a modelem niepewność modelu powinna być uwzględniona już na etapie projektu predykcyjnego algorytmu sterowania, co można zrobić używając analitycznego modelu niepewności. Zgodnie z powyższym, zaprezentowano idee takie jak: szybka selekcja modelu, dynamiczny sektor przełączenia, dwu fazowe podejście do projektu predykcyjnego algorytmu sterowania.

Słowa kluczowe: modelowanie, systemy sterowania, układ regulacji 


\section{Introduction}

The first studies on predictive control $\mathrm{MPC}^{1}$ appeared as early as in 60's of the $20^{\text {th }}$ century, but the idea became more attractive in the late 70 's after popularization of many algorithms that implement the rules for predictive control, including such algorithms as $\mathrm{DMC}^{2}, \mathrm{PFC}^{3}$, czy $\mathrm{GPC}^{4}$. The popularity that was gained by predictive approach not only among scientific circles but chiefly in industry can be explained by the easiness with which various constraints can be incorporated into the process of development and synthesis of MPC algorithms, also including the cases of multi-dimensional controlled objects.

The initial studies were limited to algorithms that considered solely a linear model of the controlled object with no constrains. Subsequently, the interest switched to algorithms where the task of square optimization with linear constraints was solved during each iteration loop. Recently, owing to availability of powerful computers with huge processing capacities, the researchers have launched studies related to the techniques of non-linear predictive control as well as predictive control under uncertain conditions. The optimization processes lead to a sequence of anticipated control stimuli that in fact depend on the adopted model.

Popular methods that make it possible to counteract consequences of uncertainty include the Discrete Adaptive Control (DAC) $)^{5}$, the min-max Robust Model Predictive Control (RMPC) ${ }^{6}$ as well as Discrete Variable Structure Control (DVSC) ${ }^{7}$.

The discrete adaptive algorithms DAC base on on-line identification of parameters attributable to the assumed model where the parameters are identified and adjusted on each step of the algorithm and serve as a basis to calculate the control signals. However, to identify the model in a correct way it is necessary to meet the condition of continuous excitation of the object, which declines the quality of the control process in case of systems with a feedback loop intended to eliminate the control error. The RMPC approach uses the min-max optimization instead of minimization of the quality factor which leads to sophisticated numerical computations that

\footnotetext{
${ }^{1}$ Ang. Model Predictive Control (MPC).

2 Ang. Dynamic Matrix Control (DMC).

${ }^{3}$ Ang. Predictive Functional Control (PFC).

${ }^{4}$ Ang. Generalized Predictive Control (GPC).

${ }^{5}$ Ang. Discrete Adaptive Control (DAC).

${ }^{6}$ Ang. min-max Robust Model Predictive Control (min-max RMPC).

${ }^{7}$ Ang. Discrete Variable Structure Control (DVSC).
} 
make their real-time implementation extremely difficult and finally brings about to the conservative control. On the other hand, the techniques with variable control structure DVSC use the idea of connectivity sector which frequently leads to problems with the implementation of this approach to objects with delayed response or in case of processes with non-minimumphases or restrained systems.

Analysis of predictive algorithms in terms of their insensitivity to disturbances is a very difficult task and no general method has been yet proposed to carry it out. It is why this study considers the occurrence of uncertainty as early as on the stage when the predictive control rule is being developed. However, to accomplish such an approach in a practical way it is necessary to apply a mathematical model of uncertainty.

The previous studies reported in literature use both parametrical and nonparametrical models. The former require the assumption of a certain structure of the model (that results from the physical description of the control process, i.e. models represented by a system of status equations developed on the basis of physical laws). Parameters of the model are not known for certain but they are characterized as they belong to a specific set. The latter require no assumptions related to the structure of the model as they are developed by superposition of disturbances with an already selected so called nominal model of the controlled object. The nominal model can be represented by means of status equations, a regressive model, timings or frequency curves. It is also possible to combine the parametrical and nonparametrical approach, which leads to a combined model.

For the purposes of this study, the parametrical description of the controlled object was selected for prediction of the object behaviour where the description is represented by status equations. It was proposed to present uncertainty as a set of models where this set is defined as a convex combination of vertex models where each vertex (node) is described by a discrete linear status equation. The additional assumption was made that at any moment of time the model that strictly adheres to the controlled object belongs to the mentioned set of vertex models.

\section{The rule of predictive control}

The predictive control intends to determine the values of the control variable $u_{(t \mid t)}, u_{(t+1 \mid t)}, \ldots, u_{(t+N-1 \mid t)}$ at subsequent moments of time $t$ on the basis of the following:

- the dynamic model of the object $M_{(t)}$;

- measurements of output signals of the object at the current moment of time $x_{(t)}$ and the preceding moments ..., $x_{(t-2)}, x_{(t-1)}$ along with the preceding values of the control signal $\ldots, u_{(t-2)}, u_{(t-1)}$; 
- already known trajectory of the input (forcing) signal $x^{z a d}$, the further assumption is that $x^{z a d}=0$.

The mentioned values of the control variable $u_{(t \mid t)}, u_{(t+1 \mid t)}, \ldots, u_{(t+N-1 \mid t)}$ are determined in such a way that the difference between the assumed trajectory $x^{z a d}$ and the anticipated trajectory $x_{(t+k \mid t)}$ expected at the prediction horizon $N$ should be minimized. Minimization of the mentioned discrepancy should be understood as optimization of a specific factor that represents the quality of control. Therefore, only the first component $\hat{u}_{(t \mid t)}$ within the optimum sequence of control signals shall be used to control the object.

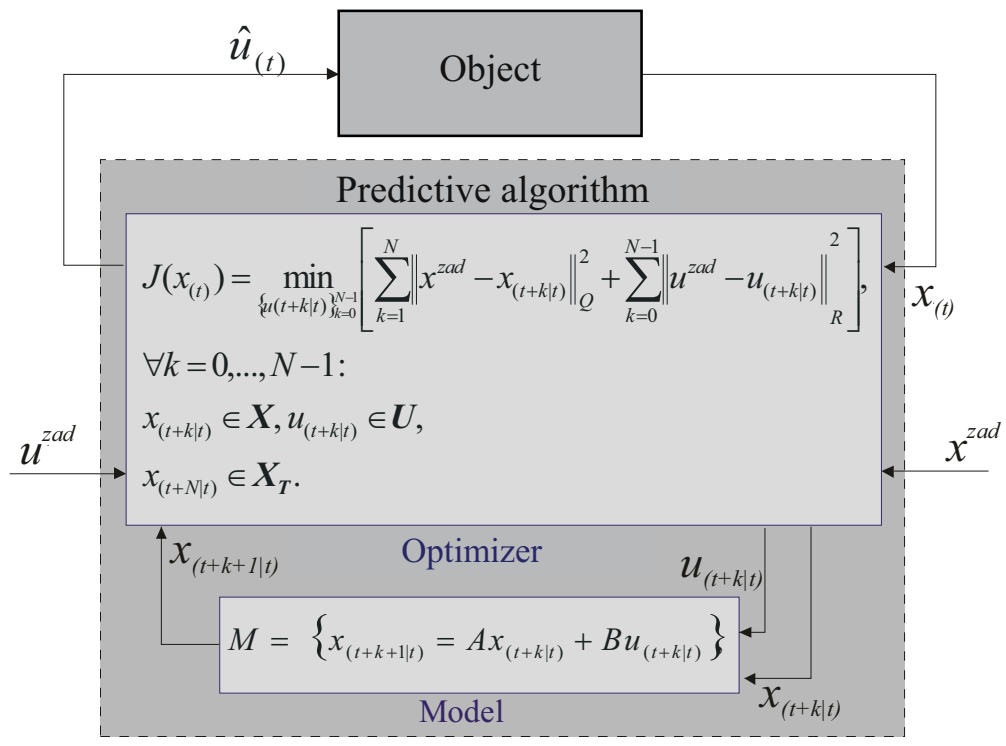

Fig. 1 The rule of predictive control

where:

- $x \in \mathfrak{R}^{n_{x}}, u \in \mathfrak{R}^{n_{u}}$ - accordingly the status and the control vectors;

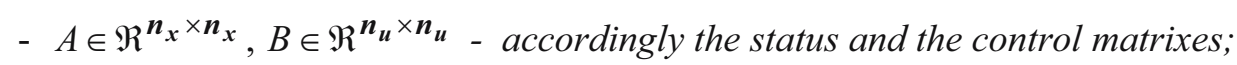

- $\mathfrak{R}^{n \times n}$ - the $n$-dimensional vector space over the algebraic field of real numbers;

- the pair of matrixes $A$ and $B$ is controllable;

- matrixes of values for penalty weights met the conditions $0<Q \in \mathfrak{R}^{\boldsymbol{n}_{\boldsymbol{x}} \times \boldsymbol{n}_{\boldsymbol{x}}}, 0<R \in \mathfrak{R}^{\boldsymbol{n}_{\boldsymbol{u}} \times \boldsymbol{n}_{\boldsymbol{u}}} ;$

- $\boldsymbol{X}$ is a set of constraints for the status, where $0 \in \boldsymbol{X}$;

- $\boldsymbol{U}$ is a compact set of constraints to the control, where $0 \in \boldsymbol{U}$;

- $\boldsymbol{X}_{\boldsymbol{T}}=\left\{x: x \in \boldsymbol{X}, u=K_{T} x \in \boldsymbol{U}\right\} \in \boldsymbol{\aleph}_{\boldsymbol{P I n} \boldsymbol{v}}$ is the compact set of final statuses as well as $0 \in \boldsymbol{X}_{T} ; \boldsymbol{\aleph}_{\boldsymbol{P I n v}}$ is a family of invariant sets. There is also a linear optimizer of the feedback loop within each of the sets $\boldsymbol{X}_{T} \in \boldsymbol{N}_{\text {PInv }}$ intended to keep the object trajectory inside $\boldsymbol{X}_{T}$ and intended to bring the trajectory to the zero point of 
equilibrium. Since the moment when the status achieves the set $\boldsymbol{X}_{T}$ the object is controlled by means of the signal with the value $u_{(t)}=K_{T} x_{(t)}$. The related methods that enable the determination of the $\boldsymbol{X}_{T}$ set can be found in relevant studies.

The rule of predictive control is exactly the same for each implementation of the algorithm. But the individual feature of each specific implementation is the model of the controlled process and/or the form of the quality factor. It is why the predictive approach can be and is actually applied to such areas as:

- banking and stock exchange

- productive modelling to support the strategy to retain customers,

- management of the investment portfolio.

- management systems - the system SAP R/3, the Business-Objects module;

- database servers - optimization of inquiries to MS SQL Server starting from the revision of 2008;

- targeting and tracking systems;

- weapon systems - trajectory of aerial bombs and intelligent missiles;

- aviation:

- predictive control over flights of robot planes at low elevations,

- navigation and flight control systems for small robot helicopters,

- predictive control with a model based on neuron networks applicable to automatic systems for flight control;

\section{Example 1}

Let us consider a controlled object where its exact model within the vicinity of its working point $x_{w}=0$ is defined by means of the following relation (1).

$$
M^{1}=\left\{\begin{array}{c}
x_{(t+k+1)}=A_{\text {model }}^{1} x_{(t|+k| t)}+B_{\text {model }}^{1} u_{(t+k \mid t)} \\
A_{\text {model }}^{1}=\left[\begin{array}{cc}
0 & 1 \\
-0.7 & 1
\end{array}\right], B_{\text {model }}^{1}=\left[\begin{array}{l}
0 \\
1
\end{array}\right]
\end{array}\right\}
$$

The objective is to develop a control algorithm capable to bring the controlled object to the working point $x_{w}=0$ with the use of the restrained control signal $\left|u_{(t)}\right| \leq 1$.

In order to solve the task the following scheme of the predictive algorithm shall be used: at each moment of time $t$ the following problem of minimization is to be solved (2): 


$$
\begin{aligned}
& J\left(x_{(t)}\right)=\min _{\{u(t+k \mid t)\}_{k=0}^{N-1}}\left[\sum_{k=1}^{N}\left\|x_{(t+k \mid t)}\right\|_{Q}^{2}+\sum_{k=0}^{N-1}\left\|u_{(t+k \mid t)}\right\|_{R}^{2}\right] \\
& \forall k=0, \ldots, N-1: \\
& u_{(t+k \mid t)} \in \boldsymbol{U}=\{u:|u| \leq 1\} \\
& x_{(t \mid t)}=x_{(t)} \\
& x_{(t+k+1 \mid t)}=A_{\text {model }}^{1} x_{(t+k \mid t)}+B_{\text {model }}^{1} u_{(t+k \mid t)}
\end{aligned}
$$

After the adjustment of the model the following values of parameters are obtained: prediction horizon $N=3$, matrixes $Q=\operatorname{diag}\{1,1\}$ and $R=[0,01]$. The timings for status variables and the control signal for the initial status $x_{(0)}=\left[\begin{array}{ll}1 & 0\end{array}\right]^{\mathrm{T}}$ and disturbances defined in Table 1 are shown in Fig. 2

Table1 Time moments of disturbances

\begin{tabular}{|c|c|}
\hline Time moments & Disturbance: $\boldsymbol{x}_{(t)}+\boldsymbol{x}_{\boldsymbol{d}}$ \\
\hline$t=10$ & $x_{d}=\left[\begin{array}{ll}-0.9 & -0.9\end{array}\right]^{\mathrm{T}}$ \\
\hline$t=19$ & $x_{d}=\left[\begin{array}{ll}0.7 & 0.7\end{array}\right]^{\mathrm{T}}$ \\
\hline$t=25$ & $x_{d}=\left[\begin{array}{ll}-0.8 & -0.8\end{array}\right]^{\mathrm{T}}$ \\
\hline
\end{tabular}
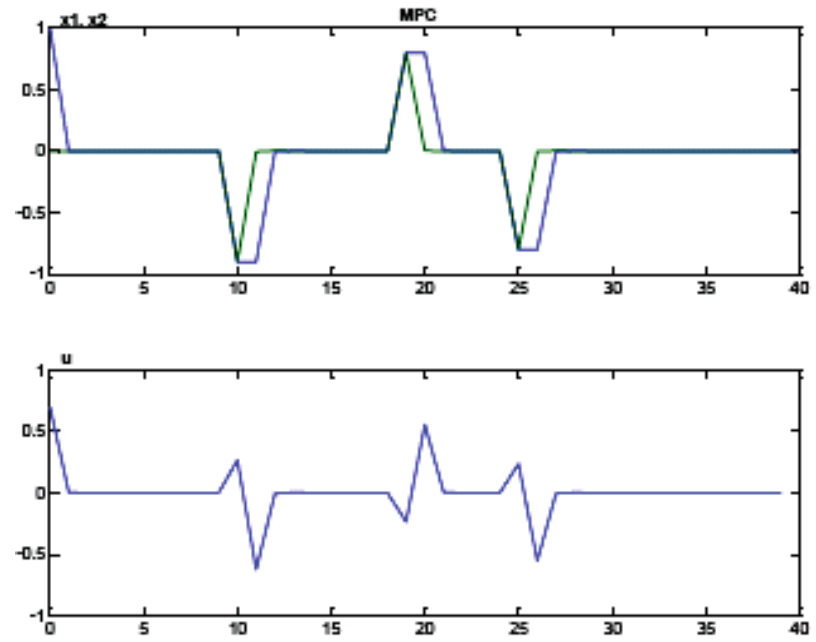

Fig. 2 The MPC algorithm with the $M^{l}$ model. The controlled object: $O=M^{l}$, with disturbances defined in Table 11.1. The timings respectively from top to bottom present status variables $x_{1(t)}, x_{2(t)}$ and the control signal $u_{(t)}$

Let us have a close look at the obtained results. At each moment of time $t$ the model (1) can be used to calculate the optimum sequence 


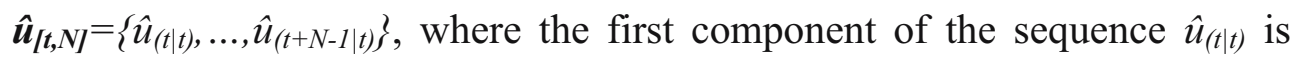
used to control the actual object. The determined control signal implicitly depends on the adopted model $M$. It is why the following question appears: What are the consequences of the discrepancy between the object and the model?

\section{Example 2}

Let us assume that the actual controlled object is defined by the model (3) but the value of the control signal is still calculated with the use of the algorithm based on the (1).

$$
M^{2}=\left\{\begin{array}{l}
x_{(t+k+1)}=A_{\text {model }}^{2} x_{(t|+k| t)}+B_{\text {model }}^{2} u_{(t+k \mid t)} \\
A_{\text {model }}^{2}=\left[\begin{array}{cc}
0 & 1 \\
-0.85 & 1
\end{array}\right], B_{\text {model }}^{2}=\left[\begin{array}{l}
0 \\
1
\end{array}\right]
\end{array}\right\}
$$

For the same operating conditions as in Example 1 the timings for status and control variables within the control system are shown in Fig. 3.
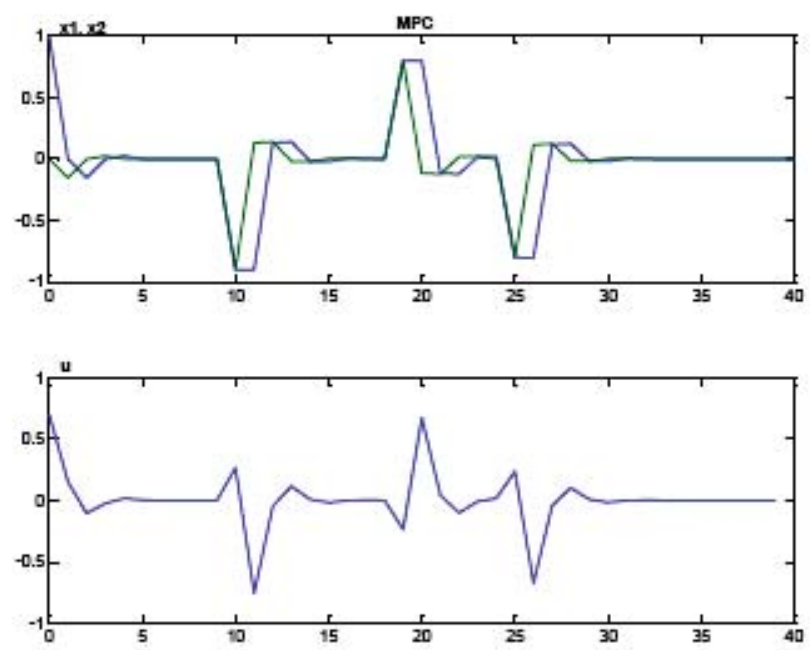

Fig. 3 The MPC algorithm with the $M^{l}$ model. The controlled object: $O=M^{2}$, with disturbances defined in Table 11.1. The timings respectively from top to bottom present status variables $x_{1(t)}, x_{2(t)}$ and the control signal $u_{(t)}$

In this case the optimization procedure of the algorithm uses the model 1 for predictions but that model differs from the real object (3). The control system is steady but the quality of control is worse, with overshooting and more prolonged transient states. The control signal exhibits more variable nature. For the both cases that have been discussed so far the controlled object was defined with steady models (1) and (3). Let us assume now that 
the algorithm is used under circumstances when the controlled object is defined by the formula (4).

$$
M^{3}=\left\{\begin{array}{c}
x_{(t+k+1)}=A_{\text {model }}^{3} x_{(t|+k| t)}+B_{\text {model }}^{3} u_{(t+k \mid t)} \\
A_{\text {model }}^{3}=\left[\begin{array}{cc}
0 & 1 \\
-1.6 & 1
\end{array}\right], B_{\text {model }}^{3}=\left[\begin{array}{l}
0 \\
1
\end{array}\right]
\end{array}\right\}
$$

Fig. 4 shows operation of the control system for the same conditions as in the case of the preceding simulations.
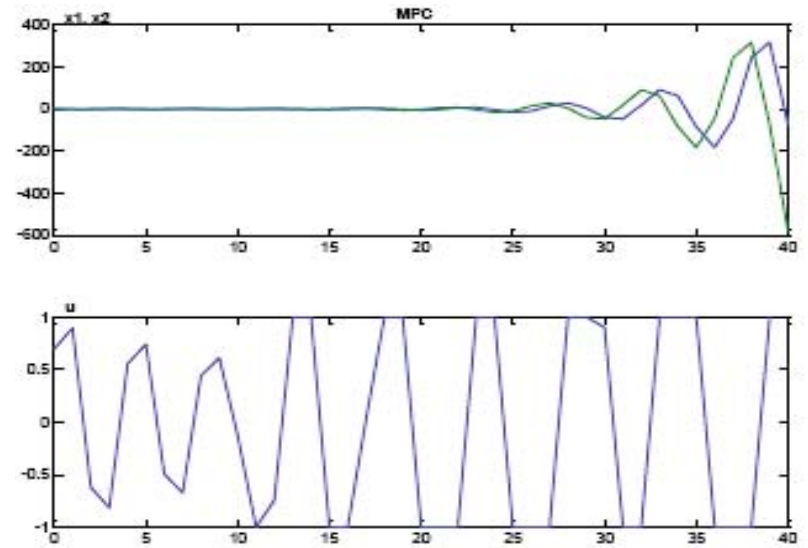

Fig. 4 The MPC algorithm with the $M^{l}$ model. The controlled object: $O=M^{3}$, with disturbances defined in Table 11.1. The timings respectively from top to bottom present status variables $x_{1(t)}, x_{2(t)}$ and the control signal $u_{(t)}$

The timings show very fast growth of status variables amplitudes whilst the control signal is toggled from one limit value to the opposite one. The MPC algorithm is not capable to stabilize the control system.

It turns out that substantial discrepancies between the real process and its model may lead to unstable operation of the control system. Taking account of the above one can formulate the answer to the foregoing question about consequences entailed by the application of an inaccurate model: the erroneous model may decrease the quality of control or even lead to destabilization of the control system. However, it is not the rule that the consequences are always so serious. At any moment of time the MPC algorithm uses on-line measurements of signals from the controlled object and uses them to calculate the control parameter. It is the feedback loop that may alleviate consequences resulting from the application of an incorrect model, however, it is not the general rule as one could see from the previous example. There is a need to use efficient methods capable to analyze 
conventional algorithms for predictive control and develop new reliable ones. In order to asses the sensitivity of the algorithm it is necessary to incorporate new developments of reliable MPC algorithms with a kind of formal mathematical methods that are capable to take account for the uncertainty even on the development stage of predictive algorithms. That formal mathematics shall be referred to as the model of uncertainty.

\section{Analytic representation of uncertainty}

\subsection{Uncertainty and reasons for its occurrence}

In a common language, uncertainty occurs when the knowledge about the subject is insufficient at the moment of uttering any statement about the relevant subject.

Uncertainty in algorithms of predictive control exists at the moment of determining control signals for the object if the information about the object is incomplete at the moment when the decision on the control variable is made.

It means that:

- lack of knowledge about objects leads to inaccurate models. Uncertainty is 'embedded' into the model as a result of the fact that an inappropriate predictive algorithm was adopted where the linear model of the controller process was assumed instead of the non-linear one due to either inaccurate identification of values for the model parameters or omission in consideration of uncontrolled inputs;

- uncertainty may occur at any moment of time, so it is necessary to wisely combat consequences of its occurrence by appropriate adjustment of the nominal MPC algorithm or by taking account of uncertainty as early as on the development stage of the predictive optimizer.

The systems for predictive control suffer from uncertainty due to the following facts:

- simplifications that consist in neglecting high degree dynamic properties (the frequent assumption is made that the behaviour of the object is defined well enough by the immediate or delayed two-inertial models),

- inaccurate estimation of time constants, gain and delays coefficients that are attributable to the object;

- neglecting non-linearity of the object;

- external interference signals;

- erroneous measurements of signals from the object; 
- lack of up-to-date information about the object, estimation of signals that are unavailable for measurements.

\subsection{Modelling of uncertainty}

The completed simulations provide the proof that the behaviour of the predictive control system depends on the model applied. It is caused by the fact that the selected model $M$ affects the form of the task (2) and consequently its solutions. As it was mentioned before, the assessment of the sensitivity and the development of a reliable algorithm requires a mathematical model of uncertainty. The literature provides two categories of such models: parametrical and non-parametrical ones. Models classified to the former category require the assumption of a preliminary structure with parameters that cannot be known with sufficient accuracy but they are characterized by affiliation to a specific set. The models of the latter category need no assumption with regard to structure of the model and they are usually developed by superposition of disturbances with an already selected so called nominal model of the controlled object. The nominal object can be presented by means of its timings or frequency curves, status equations or a regressive model. It is also possible to combine the parametrical and non-parametrical approach, which leads to a combined model.

Parametrical models of uncertainty:

- models defined by a set of impulse responses. The uncertainty is modelled by variability intervals of $b_{(t)}$ parameters:

$$
\boldsymbol{M}=\left\{y_{(t)}=\sum_{k=0}^{N_{u}} b_{(t)} u_{(t-k)}: b_{(t)} \in\left[b_{(t) \min } ; b_{(t) \max }\right], t=1, \ldots, N_{u}\right\}
$$

- models defined by a set of step responses. The uncertainty is modelled, just as in the previous case, by variability intervals of $s_{(t)}$ parameters:

$$
\boldsymbol{M}=\left\{y_{(t)}=\sum_{k=0}^{N_{u}} s_{(t)}\left(u_{(t-k)}-u_{(t-k-1)}\right): s_{(t)} \in\left[s_{(t) \min } ; s_{(t) \max }\right], t=1, \ldots, N_{u}\right\}
$$

- models defined by regressive equations. The uncertainty is defined by sets of affiliation coefficient within the following difference equation:

$$
\boldsymbol{M}=\left\{y_{(t)}=\sum_{i=1}^{N_{y}} a_{(i)} y_{(t-i)}+\sum_{i=1}^{N_{u}} b_{(i)} u_{(t-i)}:\left\{\begin{array}{l}
a_{(i)} \in\left[a_{(i) \min } ; a_{(i) \max }\right], i=1, \ldots, N_{y} \\
b_{(i)} \in\left[b_{(i) \min } ; b_{(i) \max }\right], i=1, \ldots, N_{u}
\end{array}\right\}\right.
$$

- models defined by status equations. The uncertainty is defined by the so called multi-object model, where matrixes of status equations may adopt values from the finite set of coefficients:

$$
\boldsymbol{M}=\left\{x_{(t+1)}=A_{i} x_{(t)}+B_{i} u_{(t)}:\left(A_{i}, B_{i}\right) \in\left\{\left(A_{j}, B_{j}\right)\right\}_{j=1}^{L}\right\}
$$


or by so called polyhedron model, understood as a convex combination of vertex models where each model is represented by secrete linear status equations:

$$
\boldsymbol{M}=\left\{x_{(t+1)}=A_{(t)} x_{(t)}+B_{(t)} u_{(t)}:\left(A_{(t)}, B_{(t)}\right) \in \operatorname{co}\left\{\left(A_{j}, B_{j}\right)\right\}_{j=1}^{L}\right\}
$$

Non-parametrical models of uncertainty:

- non-parametrical models: for a certain set $\boldsymbol{V}_{(t)}$ the signal $v_{(t)} \in \boldsymbol{V}_{(t)}$ is added to the nominal model $x_{(t+1)}=A x_{(t)}+B u_{(t)}$ where the incorporated signal represents the uncertainty:

$$
\boldsymbol{M}=\left\{x_{(t+1)}=A x_{(t)}+B u_{(t)}+v_{(t)}: v_{(t)} \in \boldsymbol{V}_{(t)}\right\}
$$

Combined models of uncertainty:

- for certain sets $\boldsymbol{W}_{(t)}$ i $\boldsymbol{V}_{(t)}$ and for assumed relations $A: \boldsymbol{W}_{(t)} \rightarrow \mathfrak{R}^{n \boldsymbol{n} \times \mathrm{nx}}$ $B: \boldsymbol{W}_{(t)} \rightarrow \Re^{n u \times n u}$, a so called combined model of uncertainty is obtained by superposition of both parametrical and non-parametrical descriptions:

$$
\boldsymbol{M}=\left\{x_{(t+1)}=A\left(w_{(t)}\right) x_{(t)}+B\left(w_{(t)}\right) u_{(t)}+v_{(t)}: w_{(t)} \in \boldsymbol{W}_{(t)}, v_{(t)} \in \boldsymbol{V}_{(t)}\right\}
$$

The most general representation of uncertainty is provided by the description in the form of convex combination comprising vertex models. The formula (9) uses status equations as vertex models but also difference regressive equations or step or impulse responses can be used instead. The uncertainty model that is defined in such a manner can be easily incorporated to the new development or used for analysis of a predictive control algorithm. It is why the parametrical description was assumed in this study for prediction of behaviour demonstrated by an uncertain controlled object (9). The uncertainty is represented by the set $\boldsymbol{M}$ whilst the key presumption for the further considerations is the supposition that at any moment of time $t$ the model that corresponds to the object $O$ : $x_{(t+1)}=A_{(t)}^{\text {object }} x_{(t)}+B_{(t)}^{\text {object }} u_{(t)}$ belongs to the set $\boldsymbol{M}(11.9)$, i.e. $O \in M$.

Therefore, to be able to efficiently counteract the occurrence of uncertainty, the latter must be taken into account already on the early stage of the control system development with the consideration of the following two postulations:

\section{Postulation 1}

The knowledge about the controlled object must be verified and updated on current basis during the control process with appropriate modifications of its model in order to prevent from permanently large discrepancies between the model and the actual controlled object. 
When the first postulation is fulfilled the second one can be formulated:

\section{Postulation 2}

The status of uncertainty should never be the permanent one but the uncertainty may appear at any moment of time due to alterations to the working point of the system, non-measurable interferences or defects. The objective is to minimize consequences of possible uncertainty, such as decrease in quality of control and destabilization of the control system.

\section{Predictive algorithms with on-line selection of models}

\subsection{Fast Model Selection (MS)}

It is not always the case that the object model determined during the development of a predictive algorithm closely reproduces the behaviour of a real object when the control process is in progress. It is why the objectrelated information acquired during the control process should be used for perfecting of the model in accordance with the postulation 1 . The acquired information is used to update the process and tune up parameters of the control block, which leads to adaptive predictive algorithms. Anyway, the efficiency of conventional identification methods depends of the condition of so called continuous excitation of the object. When the condition is met the quality of control usually drops down.

This disadvantage is no longer attributable to the new method where the actual model is selected from the predefined set of models (Model Selection - MS) provided that both the actual object and its model belong to the set $\boldsymbol{M}$. In addition, as selection of the model is carried out on current basis during every iteration of the algorithm, the selection procedure must be performed as quickly as possible without a substantial increase of the computation resources. The desired effect can be achieved when the method is applied as described below.

For the set of models $\boldsymbol{M}$ (9) the predicted behaviour of vertex linear equations is determined from the previous value of the control variable and already measured status variables $\left(u_{(t-1)}, x_{(t-1)}\right)$. The equation for this looks like as follows:

$$
x_{(t \mid t-1)}^{j}=A_{j} x_{(t-1)}+B_{j} u_{(t-1)}, \quad j=1, \ldots, L
$$

Next, with the consideration of current measurements for the object status, a model which enables the closest approximation of the measured value $x_{(t)}$ is selected. The selection criteria consist in determination of parameters 
$\left\{\lambda_{1}, \ldots, \lambda_{L}\right\}$ which minimize the deviation norm for prediction of the status vector:

$$
\begin{aligned}
& \min _{\left\{\lambda_{j}\right\}_{j=1}^{L} \|}\left\|x_{(t)}-\sum_{j=1}^{L} \lambda_{j} x_{(t \mid t-1)}^{j}\right\|_{2} \\
& \sum_{1}^{L} \lambda_{j}=1,0 \leq \lambda_{j} \leq 1, j=1, \ldots, L
\end{aligned}
$$

On the basis of solution for the optimization task (13) the following model can be determined:

$$
\hat{M}=\left\{x_{(t+k+1 \mid t)}(\hat{M})=\sum_{j=1}^{L} \hat{\lambda}_{j} A_{j} x_{(t+k \mid t)}(\hat{M})+\sum_{j=1}^{L} \hat{\lambda}_{j} B_{j} u_{(t+k \mid t)}=\hat{A} x_{(t+k \mid t)}(\hat{M})+\hat{B} u_{(t+k \mid t)}\right\}
$$

that is subsequently used to calculate predictions for status variables that are used for the minimization task of the MPC algorithm. This process is explained on the diagram in Fig. 5.

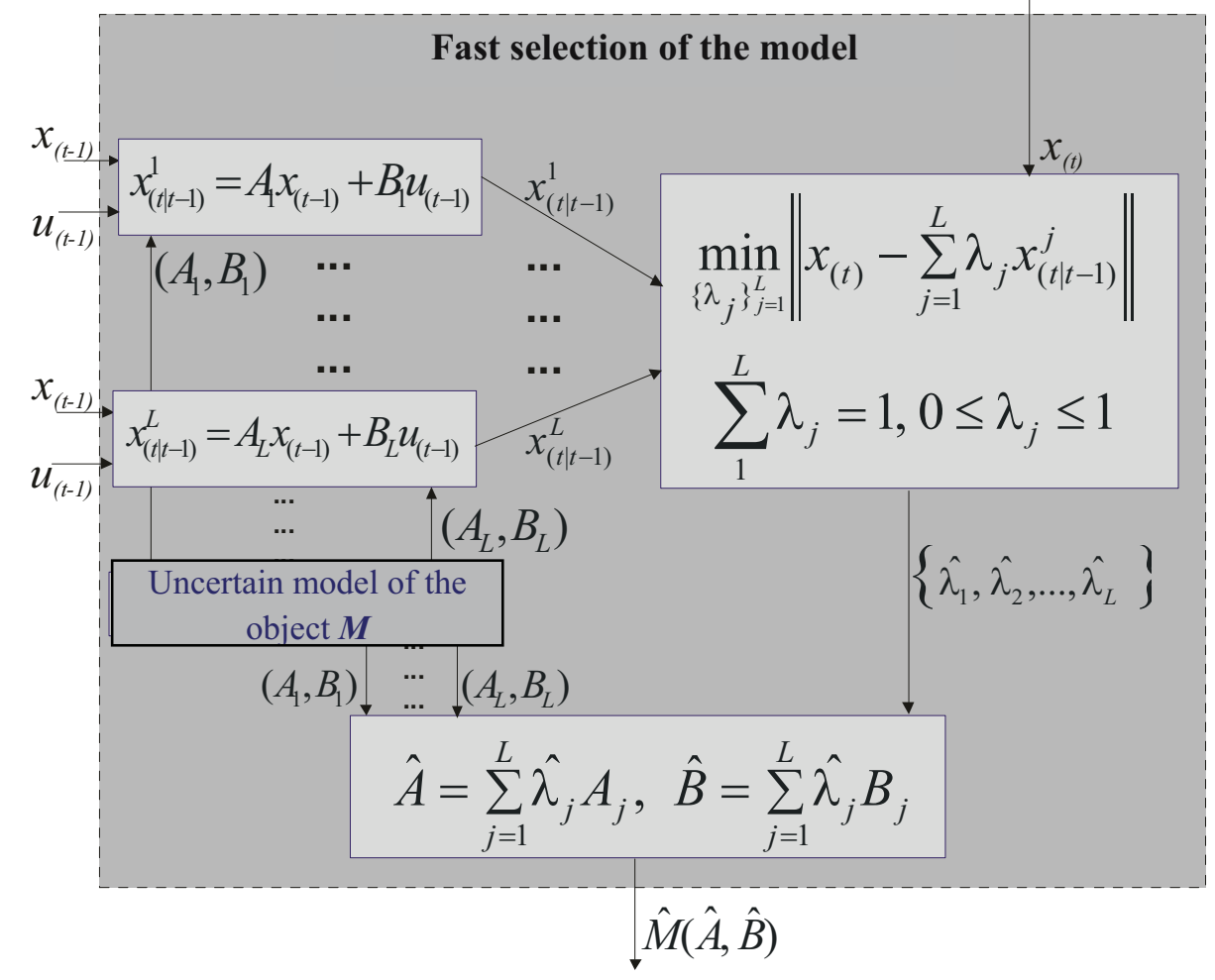

Fig. 5 Fast selection of the model 
4.2. Predictive algorithm with Model Predictive Control with fast Model Selection MPC-MS

Predictive algorithm with Model Predictive Control with fast Model Selection (MPC-MS) assumes the modification of the conventional approach MPC with consideration to Postulation 1. Implementation of the above idea consists in incorporation of steps that enable fast selection of the model into the procedure for computation of the control variable. The entire process adheres to the scheme that is described in Section 4.1.

For the uncertainty model $\boldsymbol{M}(9)$ the formal workflow diagram for a single iteration of the MPC-MS algorithm is presented in Fig. 6. The procedure is carried out in such a way that the following steps are performed at each moment of time $t$ :

1. The problem of optimum model selection (15) is resolved and the optimum model $\hat{M}$ is determined on the basis of this solution:

$$
\begin{gathered}
\hat{\lambda}=\arg \min _{\left\{\lambda_{j}\right\}_{j=1}^{L}}\left\|x_{(t)}-\sum_{j=1}^{L} \lambda_{j} x_{(t \mid t-1)}^{j}\right\|_{2} \\
\forall_{j=1 \div L} x_{(t \mid t-1)}^{j}=A_{j} x_{(t-1)}+B_{j} u_{(t-1)} \\
\sum_{1}^{L} \lambda_{j}=1,0 \leq \lambda_{j} \leq 1, j=1, \ldots, L \\
\hat{M}=\left\{\begin{array}{c}
x_{(t+k+1 \mid t)}(\hat{M})=\sum_{j=1}^{L} \hat{\lambda}_{j} A_{j} x_{(t+k \mid t)}(\hat{M})+\sum_{j=1}^{L} \hat{\lambda}_{j} B_{j} u_{(t+k \mid t)}= \\
=\hat{A} x_{(t+k \mid t)}(\hat{M})+\hat{B} u_{(t+k \mid t)}
\end{array}\right\}
\end{gathered}
$$

2. The control value is calculated according to the rule of predictive control on the basis of the diagram (16). 


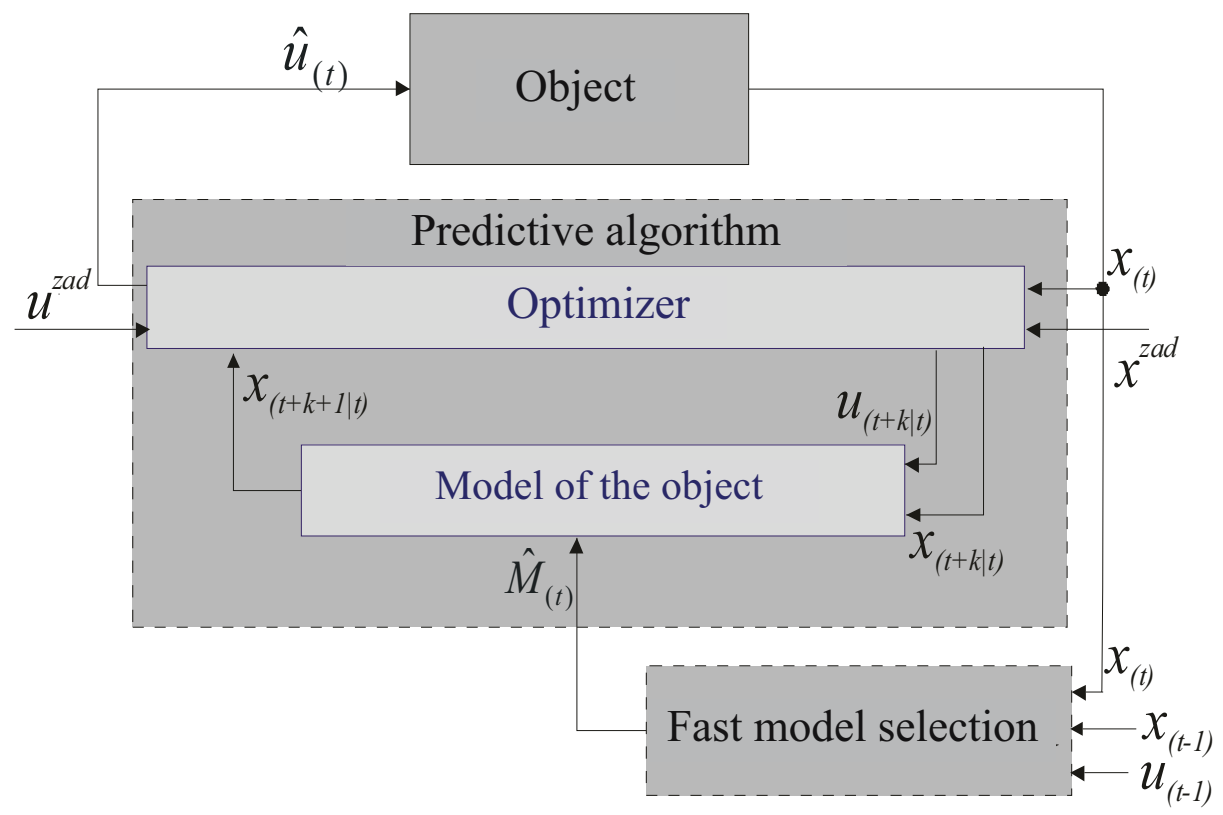

Fig. 6 Predictive algorithm with Model Predictive Control with fast Model Selection MPC-MS

$$
\begin{aligned}
& J\left(x_{(t)}\right)=\min _{\{u(t+k \mid t)\}_{k=0}^{N-1}}\left[\sum_{k=1}^{N}\left\|x_{(t+k \mid t)}(\hat{M})\right\|_{Q}^{2}+\sum_{k=0}^{N-1}\left\|u_{(t+k \mid t)}\right\|_{R}^{2}\right] \\
& \forall k=0, \ldots, N-1: \\
& u_{(t+k \mid t)} \in \boldsymbol{U}, x_{(t+k+1 \mid t)}(\hat{M}) \in \boldsymbol{X} \\
& x_{(t \mid t)}(\hat{M})=x_{(t)} \\
& \hat{M}=\left\{\begin{array}{l}
x_{(t+k+1 \mid t)}(\hat{M})=\hat{A} x_{(t+k \mid t)}(\hat{M})+\hat{B} u_{(t+k \mid t)} \\
(\hat{A}, \hat{B})=\left(\sum_{j=1}^{L} \hat{\lambda}_{j} A_{j}, \sum_{j=1}^{L} \hat{\lambda}_{j} B_{j}\right)
\end{array}\right\} \\
& x_{(t+N \mid t)}(\hat{M}) \in X_{T}
\end{aligned}
$$

The MPC-MS algorithms work in a steady manner and bring the status of the controlled object to the desired value when the uncertainty factors (a sequence of the object parameters variations and disturbances) occur quite rarely or parameters vary in a continuous manner. However, one can find such cases of uncertainty when the MPC-MS algorithm fails to guarantee steady operation of the control system. 


\section{Example 3}

The task is to develop a predictive algorithm intended to bring the controlled object to the working point $x_{w}=0$ by means of the restrained control signal $\left|u_{(t)}\right| \leq 1$. Let us assume that the control system is operated under conditions of uncertainty as described in Tables 2 and 3.

The identification procedure makes it possible to obtain a model of uncertainty (17) that serves as a basis to develop the MPC-MS algorithm. The obtained model of uncertainty is defined by means of the formula (18).

$$
\begin{aligned}
& \boldsymbol{M}=\left\{\begin{array}{c}
x_{(t+1)}=A_{(t)} x_{(t)}+B_{(t)} u_{(t)}:\left(A_{(t)}, B_{(t)}\right) \in \operatorname{co}\left\{\left(A_{\text {model }}^{1}, B_{\text {model }}^{1}\right),\left(A_{\text {model }}^{3}, B_{\text {model }}^{3}\right)\right\}= \\
\left.\left.\operatorname{co}\left\{\left(\begin{array}{cc}
0 & 1 \\
-0.7 & 1
\end{array}\right],\left[\begin{array}{l}
0 \\
1
\end{array}\right]\right),\left(\begin{array}{cc}
0 & 1 \\
-1.6 & 1
\end{array}\right],\left[\begin{array}{l}
0 \\
1
\end{array}\right]\right)\right\}
\end{array}\right\} \\
& J(x(t))=\min _{\{u(t+k \mid t)\}_{k=0}^{N-1}}\left[\sum_{k=1}^{N}\left\|x_{(t+k \mid t)}(\hat{M})\right\|_{Q}^{2}+\sum_{k=0}^{N-1}\left\|u_{(t+k \mid t)}\right\|_{R}^{2}\right] \\
& \forall k=0, \ldots, N-1 \text { : } \\
& u_{(t+k \mid t)} \in \boldsymbol{U}=\{u:|u| \leq 1\} \\
& x_{(t \mid t)}(\hat{M})=x_{(t)} \\
& \hat{M}=\left\{x_{(t+k+1 \mid t)}(\hat{M})=\hat{A} x_{(t+k \mid t)}(\hat{M})+\hat{B} u_{(t+k \mid t)},(\hat{A}, \hat{B})=\left(\sum_{j=1}^{L} \hat{\lambda}_{j} A_{j}, \sum_{j=1}^{L} \hat{\lambda}_{j} B_{j}\right)\right\}
\end{aligned}
$$

Under the initial conditions $x_{(0)}=\left[\begin{array}{ll}1 & 0\end{array}\right]^{\mathrm{T}}$ and $M_{(0)}=M^{4}$ the timings for status variables, control and selection parameters $\lambda_{1}, \lambda_{2}$ were obtained as shown in Fig. 7. The timing curve evidences unsteady operation of the control system with the MPC-MS algorithm.

$$
M^{4}=\left\{\begin{array}{c}
x_{(t+k+1)}=A_{\text {model }}^{4} x_{(t|+k| t)}+B_{\text {model }}^{4} u_{(t+k \mid t)}, \\
A_{\text {model }}^{4}=\left[\begin{array}{cc}
0 & 1 \\
-1.2 & 1
\end{array}\right], B_{\text {model }}^{4}=\left[\begin{array}{l}
0 \\
1
\end{array}\right]
\end{array}\right\}
$$

Table 2

Occurrence of uncertainty

\begin{tabular}{|c|c|}
\hline Time moments & Process \\
\hline$t=0 \div 5$ & $M^{1}: A_{\text {model }}^{1}=\left[\begin{array}{cc}0 & 1 \\
-0.7 & 1\end{array}\right], B_{\text {model }}^{1}=\left[\begin{array}{l}0 \\
1\end{array}\right]$ \\
\hline $\begin{array}{l}\text { for the remaining } \\
\text { moments of time }\end{array}$ & $M^{3}: A_{\text {model }}^{3}=\left[\begin{array}{cc}0 & 1 \\
-1.6 & 1\end{array}\right], B_{\text {model }}^{3}=\left[\begin{array}{l}0 \\
1\end{array}\right]$ \\
\hline
\end{tabular}


Table 3 Time moments of disturbances

\begin{tabular}{|c|c|}
\hline Time moments & Disturbance: $\boldsymbol{x}_{(t)}+\boldsymbol{x}_{\boldsymbol{d}}$ \\
\hline$t=10$ & $x_{d}=\left[\begin{array}{ll}-0.8 & 0.8\end{array}\right]^{\mathrm{T}}$ \\
\hline$t=14$ & $x_{d}=\left[\begin{array}{ll}-0.8 & 0.8\end{array}\right]^{\mathrm{T}}$ \\
\hline$t=19$ & $x_{d}=\left[\begin{array}{ll}0.8 & -0.8\end{array}\right]^{\mathrm{T}}$ \\
\hline$t=21$ & $x_{d}=\left[\begin{array}{ll}-0.7 & 0.7\end{array}\right]^{\mathrm{T}}$ \\
\hline$t=25$ & $x_{d}=\left[\begin{array}{ll}0.7 & -0.7\end{array}\right]^{\mathrm{T}}$ \\
\hline
\end{tabular}
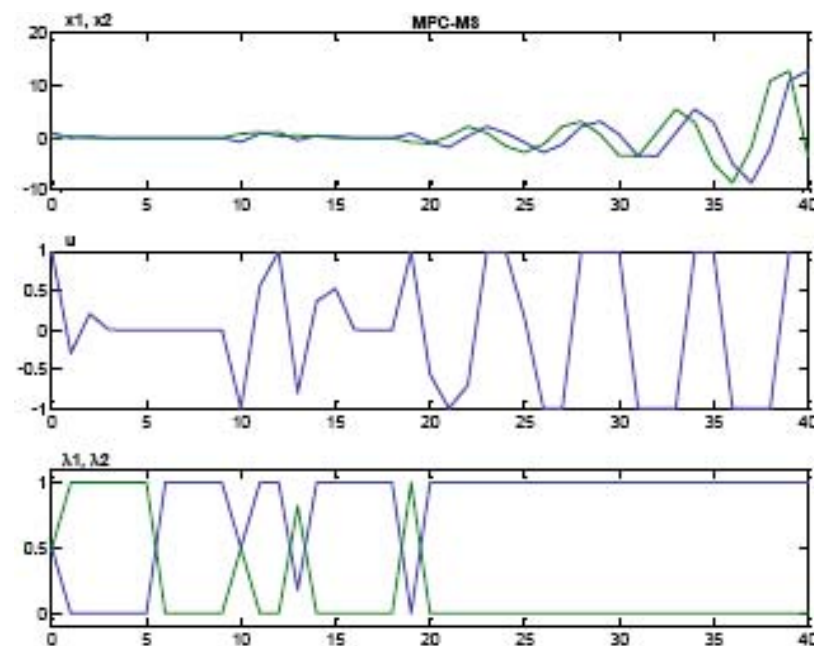

Fig 7 The MPC-MS algorithm with object uncertainty described in Table2 and disturbances defined in Table 3. The timings respectively form to bottom present status variables $x 1(t), x 2(t)$, the control signal $u(t)$ and model selection parameters \&\#955;1, \&\#955;2.

a. Predictive algorithms for Robust Model Predictive Control (RMPC). with min-max optimization

The content of the Postulation 2 can be responded with robust predictive algorithms with min-max optimization. Substitution of the quality factor with the min-max task is intended to select the toughest conditions in terms of uncertainty and combat them by means of the robust predictive algorithm. It enables to incorporate the description of uncertainty into the comprehensive quality factor and use the uncertainty model for calculation of the control signal in the way that makes it possible to achieve the algorithm that guarantees robust quality of control.

Each iteration loop of the RMPC algorithm (see Fig. 8) is executed in the following way: at each moment of time $t$ the problem of the following form (20) is to be solved: 


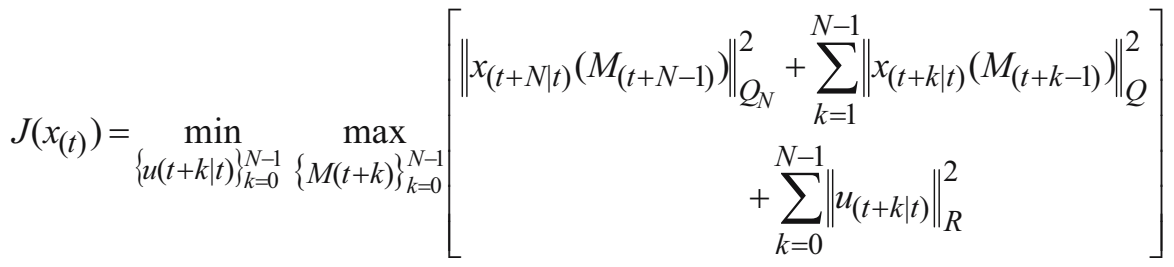

$$
\begin{aligned}
& \forall k=0, \ldots, N-1 \text { : } \\
& u_{(t+k \mid t)} \in \boldsymbol{U}, M_{(t+k)} \in \boldsymbol{M},\left(A_{(t+k)}, B_{(t+k)}\right) \in \operatorname{co}\left\{\left(A_{j}, B_{j}\right)\right\}_{j=1}^{L} \\
& x_{(t \mid t)}=x_{(t)}, \quad X_{0}=\left\{x_{(t)}\right\} \\
& M_{(t+k)}=\left\{\begin{array}{l}
k=0: x_{(t+1 \mid t)}\left(M_{(t)}\right)=A_{(t)} x_{(t \mid t)}+B_{(t)} u_{(t \mid t)} \\
\forall k=1, \ldots, N-1: x_{(t+k+1 \mid t)}\left(M_{(t+k)}\right)=A_{(t+k)} x_{(t+k \mid t)}\left(M_{(t+k-1)}\right)+B_{(t+k)} u_{(t+k \mid t)},
\end{array}\right\} \\
& \bigcup \bigcup^{L}\left\{x_{(k+1)}^{j}: x_{(k+1)}^{j}=A_{j} x+B_{j} u_{(t+k \mid t)}\right\}=\boldsymbol{X}_{\boldsymbol{k}+\boldsymbol{1}} \subset \boldsymbol{X} \\
& x \in X_{k} j=1 \\
& \boldsymbol{X}_{\boldsymbol{N}} \subset \boldsymbol{X}_{T}
\end{aligned}
$$

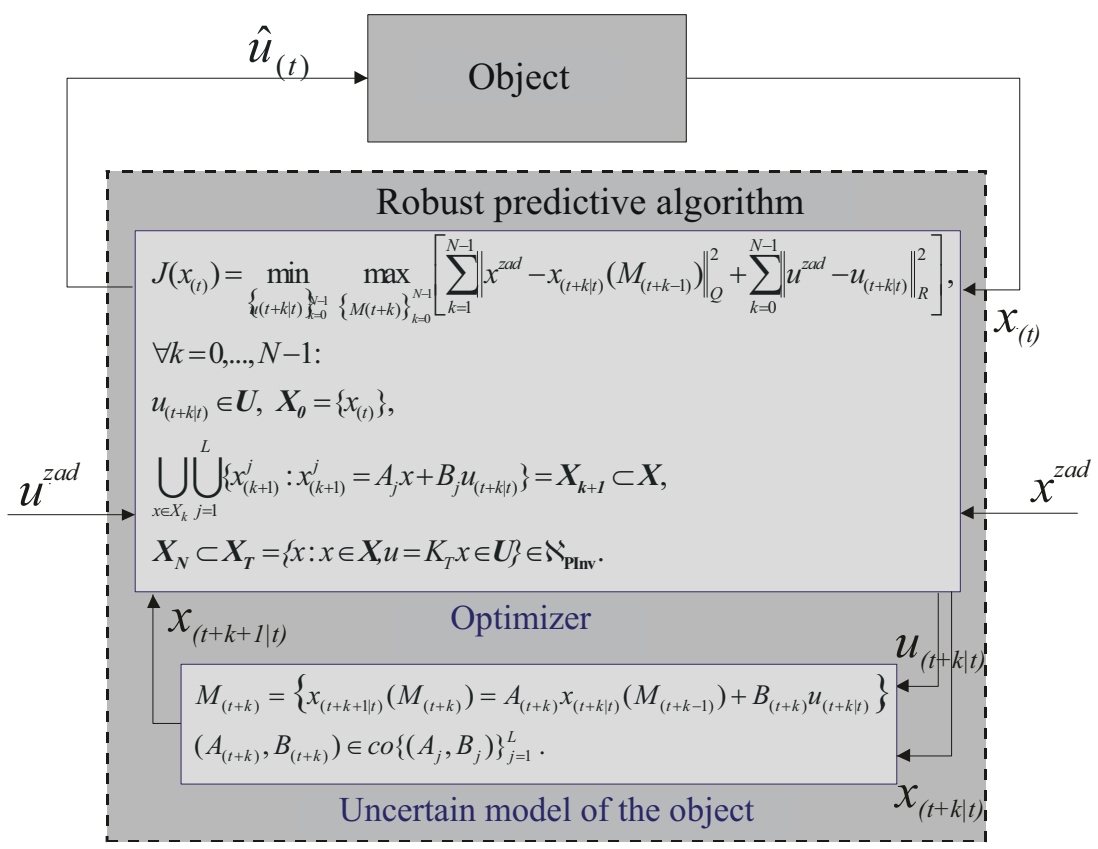

Fig. 11.8. The algorithm for Robust Model Predictive Control (RMPC)

In a general case the optimization task is not convex (20). For such types of problems it is impossible to guarantee that the solution can be found within a reasonably short time as well as no warranty can be provided that the 
obtained solution is of global nature. In addition, constraints of the task (20) are really restrictive as they must be met not only by a single trajectory of the controlled object but by the entire family of trajectories for vertex models that are defined by the assumed model of uncertainty (the equation 9). It is the reason why the set of the object statuses $\left(\widetilde{\boldsymbol{X}}_{F}\right)$ for which the optimization task has a defined solution is really limited, which was demonstrated in [2] and substantially affects the quality of control. In this study the set of statuses for which the optimization task (20) has a defined solution for each uncertainty arrangement $M \in M$ shall be referred to as the robust set of mpc-permissible statuses. It is the set that shall be used in the further part of this study for development of algorithms. The formal definition of the set $\widetilde{\boldsymbol{X}}_{F}$ can be formulated in the following way:

\section{Definition 1}

The set of all $x \in \boldsymbol{X}$ for which the task (20) has definite solutions for each uncertainty arrangement $M_{(t)} \in \boldsymbol{M}$ shall be referred to as the robust set of mpc-permissible statuses $\widetilde{\boldsymbol{X}}_{F}$.

\section{b. Discrete algorithms with variable structure of control DVSC}

The Sliding Mode Control (SMC) is one of the oldest algorithms that are classified into the group referred to as the Variable Structure Control (VSC) methods. Its primary version was proposed for systems with continuous count of time. The sliding motion was carried out on a switchover plane. For discrete systems where the switching frequency is limited by the sampling time the switchover plane was substituted with the switchover sector due to the imposed requirement of very short switchover time. It has led to development of algorithms with Discrete Variable Structure Control (DVSC).

With consideration to the Postulation 1 the idea of the dynamic switchover sector $\wp_{(t)}$ was proposed where the parameters of the sector are calculated on current basis. The model is chosen on the basis of the fast model selection and uncertainty of $\boldsymbol{M}$. Finally, the Discrete Variable Structure Control with fast Model Selection (DVSC-MS) algorithm is obtained. Each iteration of the DVSC-MS algorithm is carried out in such a manner that the following steps are carried out at each moment of time $t$ :

1. The task of fast model selection is resolved (15) that serves as the basis to calculate gain $K_{(t)}^{S}$, the set $\boldsymbol{U}_{(t)}^{S}$ and the sector $\wp_{(t)}$. 
2. New parameters are then used to calculate the control signal in accordance with the conventional workflow of the DVSC algorithm as is it shown below.

The switchover sector is defined in the following way:

$$
\begin{aligned}
& \wp=\left\{x_{(t)}|| S^{T} x_{(t)} \mid \leq \delta\left(x_{(t)}\right)\right\} \\
& S \in \mathfrak{R}^{\boldsymbol{n}_{x} \times \boldsymbol{1}} \wedge s_{n_{x}}=1, \delta\left(x_{(t)}\right)=\frac{k^{0}}{2|\beta|} \sum_{i=1}^{n_{x}}\left|x_{(t)}^{i}\right| \\
& 0<k^{0}<2|\beta| s_{\max }, s_{\max }=\max _{1 \leq i \leq n_{x}}\left|s_{i}\right|, 0<|\beta|<1
\end{aligned}
$$

where $S, \beta, k^{0}$ - parameters of the sector, values of these parameters during the tuning phase of the algorithm. For the $M$ model (from Fig. 1) and the sector (11.21) the control rule is defined in the following form:

$$
\begin{aligned}
& u_{(t)}=-\left(S^{T} B\right)^{-1}\left(S^{T} A x_{(t)}-\beta S^{T} x_{(t)}-K x_{(t)}\right) \\
& K \in \mathfrak{R}^{1 \times n_{x}}, \underset{i=1, \ldots, n_{x}}{\forall} k_{i}=\left\{\begin{array}{cc}
0 & \left|S^{T} x_{(t)}\right| \leq \delta_{(t)}\left(x_{(t)}\right) \\
-k^{0} \operatorname{sgn}\left(\beta S^{T} x_{(t)}^{i}\right) & \left|S^{T} x_{(t)}\right|>\delta_{(t)}\left(x_{(t)}\right)
\end{array}\right.
\end{aligned}
$$

Although the presented algorithm demonstrates high insensitivity to uncertainty conditions it is not free of drawbacks that include:

- no possibility to take account for constraints when the control system is being developed,

- the algorithms may fail to operate satisfactorily with control systems that comprise component with non-minimum-phases characteristics and/or components with transfer delays;

- the sector area $\&$ defined by the relation (11.12) represents a cone with its vertex at the assigned working point. The closer to that point the narrower the area becomes. Maintaining steady state of the uncertain process within the vicinity of the working point may need fast switching of the control signal, which is not always allowed;

- sector areas, beside boundary cases, are not convex sets. Therefore, it is impossible to guarantee that the actual status of the controlled object falls within the area of $\varnothing$ if no additional constraints are imposed;

- no mechanism exist that would assign the attribute of invariance to the sector area. 
c. Discrete predictive algorithms with variable structure of control DPVSC Actually, each algorithm of the class referred to as Discrete Predictive Variable Structure Control DPVSC is a meta-algorithm and presents solely a frame to develop specific implementations of the algorithms. The characteristic feature of meta-algorithms is its switchover criterion understood as conditions that enforce alteration of the control structure after they have occurred. Any implementation (a specific release) of the algorithm determines both the initial and target structures for the switchover.

7.1. Robust Model Predictive Control with Switching Sector and fast Model Selection (RMPC-SS-MS)

The formal formulation of a single iteration for the RMPC-SS-MS ${ }^{8}$ algorithm is shown in Fig. 9 and is executed in the way as below, i.e. the following steps are carried out at each moment of time $t$ :

1. The task of optimum selection is resolved (15) and the solution serves as the basis to determine the gain $K^{S}{ }_{(t)}$ and the switchover sector $\wp_{(t)}$.

2. If $x_{(t \mid t)} \in \boldsymbol{X}_{T}$, then the control function is calculated by means of the following formula (23).

$$
u_{(t)}=K_{T} x_{(t)}
$$

3. Otherwise, if $x_{(t \mid t)} \notin \wp_{(t)}$ the control function is calculated with use of the predictive algorithm with its workflow defined by (24).

$$
\begin{aligned}
& J\left(x_{(t)}\right)=\min _{\{u(t+k \mid t)\}_{k=0}^{N_{1}-1}}\left[\sum_{k=1}^{N_{1}}\left\|x_{(t+k \mid t)}(\hat{M})\right\|_{Q_{1}}^{2}+\sum_{k=0}^{N_{1}-1}\left\|u_{(t+k \mid t)}\right\|_{R_{1}}^{2}\right] \\
& \forall k=0, \ldots, N_{1}-1: \\
& u_{(t+k \mid t)} \in \boldsymbol{U}=\{u:|u| \leq 1\} \\
& x_{(t \mid t)}(\hat{M})=x_{(t)} \\
& \hat{M}=\left\{x_{(t+k+1 \mid t)}(\hat{M})=\hat{A} x_{(t+k \mid t)}(\hat{M})+\hat{B} u_{(t+k \mid t)}:(\hat{A}, \hat{B})=\left(\sum_{j=1}^{L} \hat{\lambda}_{j} A_{j}, \sum_{j=1}^{L} \hat{\lambda}_{j} B_{j}\right)\right\} \\
& x_{(t+k+1 \mid t)}(\boldsymbol{M})=\bigcup_{x \in X_{k}} \bigcup_{j=1}^{L}\left\{x_{(k+1)}^{j}: x_{(k+1)}^{j}=A_{j} x+B_{j} u_{(t+k \mid t)}\right\} \\
& \operatorname{sgn}\left(S_{\perp(t)}^{T} x_{\left(t+N_{1} \mid t\right)}(\boldsymbol{M})\right) \geq 0(\text { lub } \leq 0), S_{\perp(t)}^{T} \cdot S_{(t)}=0 \\
& x_{\left(t+N_{1} \mid t\right)}(\boldsymbol{M}) \subset \wp_{(t)}
\end{aligned}
$$

\footnotetext{
${ }^{8}$ Ang. Robust Model Predictive Control with Switching Sector and fast Model Selection (RMPC-SS-MS).
} 
When the task (24) has no permissible solutions, the control function shall be calculated following the relation (25). Should the control function breach the constraint $\mid u_{(t)} \leq 1$, the control signal is rounded to the maximum allowed value.

$$
\begin{gathered}
u_{(t)}=-\left(S_{(t)}^{T} \hat{B}\right)^{-1}\left(S_{(t)}^{T} \hat{A} x_{(t)}-\beta_{(t)} S_{(t)}^{T} x_{(t)}-K x_{(t)}\right)=K_{(t)}^{O} x_{(t)} \\
K=\left[\begin{array}{llll}
-k_{(t)}^{0} \operatorname{sgn}\left(\beta_{(t)} S_{(t)}^{T} x_{(t)}^{1}\right) & -k_{(t)}^{0} \operatorname{sgn}\left(\beta_{(t)} S_{(t)}^{T} x_{(t)}^{2}\right) & \ldots & -k_{(t)}^{0} \operatorname{sgn}\left(\beta_{(t)} S_{(t)}^{T} x_{(t)}^{n_{x}}\right)
\end{array}\right]
\end{gathered}
$$

4. When the provision $x_{(t \mid t)} \in \wp_{(t)}$ is fulfilled, the control function value is calculated by means of the predictive algorithm (26).

$$
\begin{aligned}
& J\left(x_{(t)}\right)=\min _{\{u(t+k \mid t)\}_{k=0}^{N_{2}-1}}\left[\sum_{k=1}^{N_{2}}\left\|x_{(t+k \mid t)}(\hat{M})\right\|_{Q_{2}}^{2}+\sum_{k=0}^{N_{2}-1}\left\|u_{(t+k \mid t)}\right\|_{R_{2}}^{2}\right] \\
& \forall k=0, \ldots, N_{2}-1: \\
& u_{(t+k \mid t)} \in \boldsymbol{U}=\{u:|u| \leq 1\} \\
& x_{(t \mid t)}(\hat{M})=x_{(t)}, \quad \boldsymbol{X}_{\boldsymbol{O}}=\left\{x_{(t)}\right\} \\
& \hat{M}=\left\{x_{(t+k+1 \mid t)}(\hat{M})=\hat{A} x_{(t+k \mid t)}(\hat{M})+\hat{B} u_{(t+k \mid t)}:(\hat{A}, \hat{B})=\left(\sum_{j=1}^{L} \hat{\lambda}_{j} A_{j}, \sum_{j=1}^{L} \hat{\lambda}_{j} B_{j}\right)\right\} \\
& x_{(t+k+1 \mid t)}(\boldsymbol{M})=\bigcup_{x \in X_{k}} \bigcup_{j=1}^{L}\left\{x_{(k+1)}^{j}: x_{(k+1)}^{j}=A_{j} x+B_{j} u_{(t+k \mid t)}\right\}=\boldsymbol{X}_{\boldsymbol{k}+\boldsymbol{1}} \subset \wp_{(t)} \\
& \operatorname{sgn}\left(S_{\perp(t)}^{T} x_{(t+k+1 \mid t)}(\boldsymbol{M})\right) \geq 0(1 \mathrm{ub} \leq 0), S_{\perp(t)}^{T} \cdot S_{(t)}=0 \\
& x_{\left(t+N_{2} \mid t\right)}(\boldsymbol{M}) \subset \boldsymbol{X}_{\boldsymbol{T}}
\end{aligned}
$$

If no solution of the task (26) is obtained, the control function is calculated by means of the formula (27). Should the control function breach the constraint $\left|u_{(t)}\right| \leq 1$, the control signal is rounded to the maximum allowed value.

$$
u_{(t)}=-\left(S_{(t)}^{T} \hat{B}\right)^{-1}\left(S_{(t)}^{T} \hat{A} x_{(t)}-\beta_{(t)} S_{(t)}^{T} x_{(t)}\right)=K_{(t)}^{S} x_{(t)}
$$




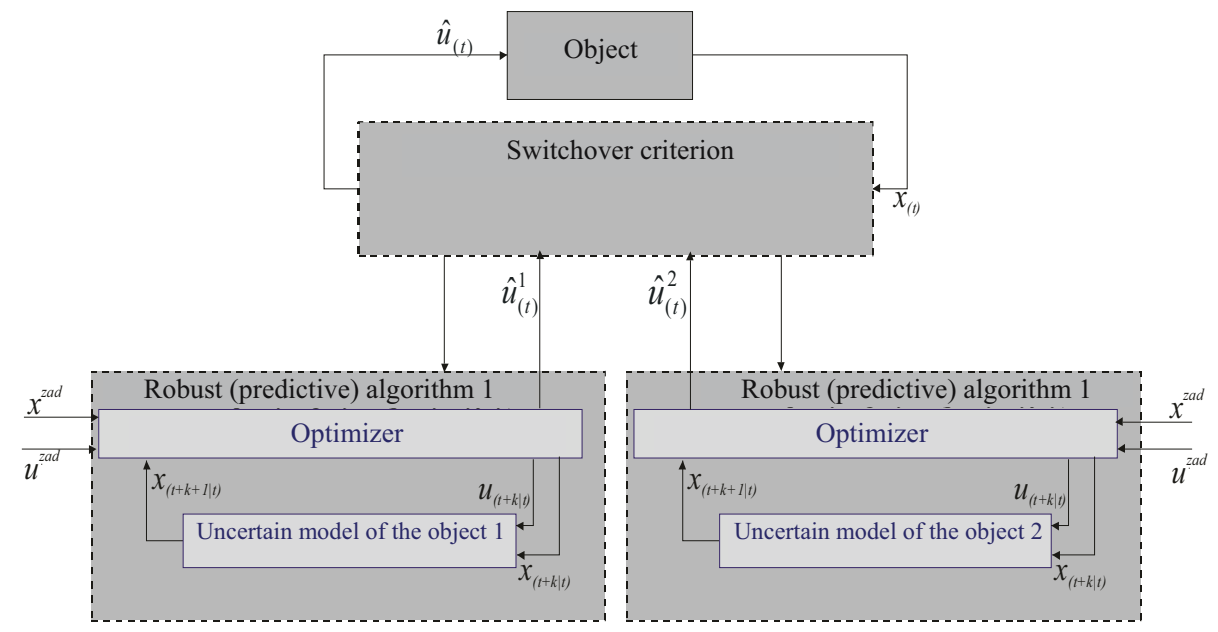

Fig. 9. The predictive algorithm RMPC-SS-MS

\section{Example 4}

The attention was focused on the behaviour of the control system according to RMPC-SS-MS algorithm under conditions as described for the Example 3, with the arrangement of uncertainty as per Tables 2 and 3 as well as the initial conditions $x_{(0)}=\left[\begin{array}{ll}1 & 0\end{array}\right]^{\mathrm{T}}, M_{(0)}=M^{4}(11.19), K_{(0)}^{S}(28)$ and the sector $\wp_{(0)}(29)$. After application of the algorithm the timings for status variables and control function were obtained as well as for pointer of the object position on the status trajectory as shown in Fig. 10.

$$
\begin{aligned}
& K^{S}=\left[\begin{array}{ll}
-1.2000 & 0.9989
\end{array}\right], \boldsymbol{U}^{S}=\left\{x:\left|K^{S} x\right| \leq 1\right\} \\
& S^{T}=\left[\begin{array}{ll}
-0.0005 & 1
\end{array}\right], S_{\perp}^{T}=\left[\begin{array}{ll}
1.8224 \cdot 10^{3} & 1
\end{array}\right] \\
& \beta=0.005, k^{0}=0.3 \cdot 2|\beta|_{\text {max }}=0.0003 \\
& \boldsymbol{X}_{T}=\boldsymbol{X}_{T}^{e}=\left\{x: x^{T}\left[\begin{array}{cc}
63.12 & -12.13 \\
-12.13 & 181.54
\end{array}\right] x \leq 10^{-8}\right\} \\
& K_{T}=\left[\begin{array}{ll}
1.1537 & -0.9245
\end{array}\right]^{T}
\end{aligned}
$$



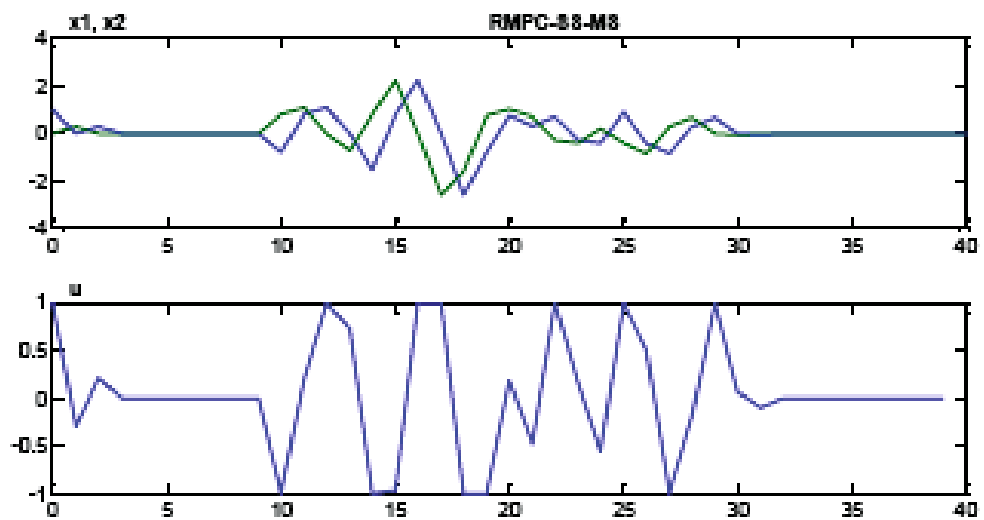

Pointer for position on the status

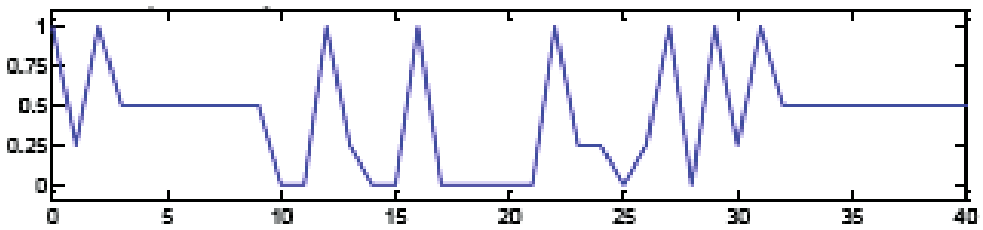

Fig. 10 The RMPC-SS-MS algorithm with the ellipse for limiting the target status (30) within the system with the constraint $\left|u_{(t)}\right| \leq 1$. The timings respectively from top to bottom present status variables $x_{1(t)}, x_{2(t)}$, the control signal $u_{(t)}$ and the pointer for position on the status trajectory: 1 -status within the sector, the control rule (27); 0.75- status within the sector, the control rule .26), 0.5- status within the set $\boldsymbol{X}_{\boldsymbol{T}}$; the control rule (23), 0.25- status outside the sector, the control rule (24), 0- status outside the sector, the control rule (25)

Fig.10 shows steady operation of the control system. The completed examinations of the RMPC-SS-MS algorithm provided the proof that it is an efficient approach for many cases but it fails to guarantee that it will still remain efficient for any arrangement of uncertainty $\boldsymbol{M}$. The assumption that predictive algorithm generate permissible control function at any moment of time with consideration of the existence of the sector is really daring and may prove infeasible. Therefore, why combine the methods that use the switchover sector with the predictive algorithms? The advantage of the RMPC-SS-MS algorithm over the RMPC approach with min-max optimization as well as the MPC-MS approach results from the fact that it provides sector-based solution when a permissible predictive control cannot be obtained, thus the set of permissible solutions shall never be empty. But the control function that is achieved in that way may be rounded to the closest permissible value when the imposed constraints are exceeded. The control systems that use control functions obtained in that way can never be subjected to a formal analysis in terms of their stability, particularly when uncertainty is to be taken into account. The advantage of the RMPC-SS-MS over the DVSC approach results from the fact that the DVSC algorithm 
neglects constrains to status variables and the control function, whereas those constraints are considered by the RMPC-SS-MS algorithms.

\subsection{The robust dual phase algorithm for predictive control with fast model selection RDP-MPC-MS}

It is known that large discrepancies between the real object and its model may lead to destabilization of the control system when the MPC-type algorithm is used. On the other hand, the robust predictive algorithm of the RMPC type is always conservative, operates slowly and demonstrates poor quality of control.

With consideration to the above and having taken account for Postulations 1 and 2, this study proposes the algorithm classified to the DPVSC class and comprising two operational phases and the phase of fast selection of the model - the RDP-MPC-MS ${ }^{9}$ algorithm. This approach consists in the fact that under rated (nominal) conditions (phase 1) the system is operated under control of a fast MPC-MS algorithm that guarantees high quality of control. However, under critical conditions (phase 2) that comprise e.g. emergency cases, variation of the working point or disturbances, the control structure is switched over to the sophisticated and time-consuming but robust algorithm of the RMPC type. Every iteration of the RDP-MPC-MS meta-algorithm (Fig.11) is executed in the way as below, i.e. the following steps are carried out at each moment of time $t$ :

1. The selection task is resolved (15) with the result in the form of the model $\hat{M}(\hat{A}, \hat{B})$.

2. If $x_{(t \mid t)} \in \boldsymbol{X}_{\boldsymbol{T}}$, then the control function is calculated by means of the following formula (31).

$$
u_{(t)}=K_{T} x_{(t)}
$$

3. The MPC phase consists in testing of the MPC algorithm, The MPCMS algorithm is launched with it workflow (32):

\footnotetext{
${ }^{9}$ Ang Robust Dual Phase Model Predictive Control with fast Model Selection (RDP-MPC-MS).
} 
$J\left(x_{(t)}\right)=\min _{\{u(t+k \mid t)\}_{k=0}^{S-1}}\left[\left\|x_{(t+N \mid t)}(\hat{M})\right\|_{Q_{N}}^{2}+\sum_{k=1}^{N-1}\left\|x_{(t+k \mid t)}(\hat{M})\right\|_{Q}^{2}+\sum_{k=0}^{N-1}\left\|u_{(t+k \mid t)}\right\|_{R}^{2}\right]$

$\forall k=0, \ldots, N-1$ :

(1) $u_{(t+k \mid t)} \in \boldsymbol{U}$

(2) $x_{(t+k+1 \mid t)}(\hat{M}) \in \boldsymbol{X}$

$x_{(t \mid t)}(\hat{M})=x_{(t)}$

$\hat{M}=\left\{x_{(t+k+1 \mid t)}(\hat{M})=\hat{A} x_{(t+k \mid t)}(\hat{M})+\hat{B} u_{(t+k \mid t)}:(\hat{A}, \hat{B})=\left(\sum_{j=1}^{L} \hat{\lambda}_{j} A_{j}, \sum_{j=1}^{L} \hat{\lambda}_{j} B_{j}\right)\right\}$

(3) $x_{(t+N \mid t)}(\hat{M}) \in \boldsymbol{X}_{\boldsymbol{T}}$

that provides the control function $\hat{u}^{M P C}(t)$. If the condition (33) is met, the signal with the $\hat{u}^{M P C}{ }_{(t)}$ is used to control the supervised object.

$$
\underset{j=1 \div L}{\forall} x^{j}(t+1 \mid t)=A_{j} x_{(t \mid t)}+B_{j} \hat{u}_{(t)}^{M P C} \in \widetilde{\boldsymbol{X}}_{\boldsymbol{F}}^{\boldsymbol{R M P C}}
$$

4. The RMPC phase. If the condition (33) is not fulfilled, the RMPC algorithm with min-max optimization is launched according to the following workflow (34):

$J\left(x_{(t)}\right)=\min _{\{u(t+k \mid t)\}_{k=0}^{N-1}} \max _{\{M(t+k)\}_{k=0}^{N-1}}\left[\begin{array}{c}\left\|x_{(t+N \mid t)}\left(M_{(t+N-1)}\right)\right\|_{Q_{N}}^{2}+\sum_{k=1}^{N-1}\left\|x_{(t+k \mid t)}\left(M_{(t+k-1)}\right)\right\|_{Q}^{2} \\ +\sum_{k=0}^{N-1}\left\|u_{(t+k \mid t)}\right\|_{R}^{2}\end{array}\right]$

$\forall k=0, \ldots, N-1:$

(1) $u_{(t+k \mid t)} \in \boldsymbol{U}$

(2) $\bigcup_{x \in X_{k}} \bigcup_{j=1}^{L}\left\{x_{(k+1)}^{j}: x_{(k+1)}^{j}=A_{j} x+B_{j} u_{(t+k \mid t)}\right\}=\boldsymbol{X}_{\boldsymbol{k}+\boldsymbol{1}} \subset \boldsymbol{X}$

$x_{(t \mid t)}=x_{(t)}, \quad \boldsymbol{X}_{\mathbf{0}}=\left\{x_{(t)}\right\}$

$M_{(t+k)}=\left\{\begin{array}{l}k=0: \\ x_{(t+1 \mid t)}\left(M_{(t)}\right)=A_{(t)} x_{(t \mid t)}+B_{(t)} u_{(t \mid t)} \\ \forall k=1, \ldots, N-1: \\ x_{(t+k+1 \mid t)}\left(M_{(t+k)}\right)=A_{(t+k)} x_{(t+k \mid t)}\left(M_{(t+k-1)}\right)+B_{(t+k)} u_{(t+k \mid t)}\end{array}\right\}$

$M_{(t+k)} \in \boldsymbol{M},\left(A_{(t+k)}, B_{(t+k)}\right) \in \operatorname{co}\left\{\left(A_{j}, B_{j}\right)\right\}_{j=1}^{L}$

(3) $\boldsymbol{X}_{N} \subset \boldsymbol{X}_{T}$ 
The algorithm provides the control function $\hat{u}_{(t)}^{R M P C}$ that is supplied to the input of the controlled object.

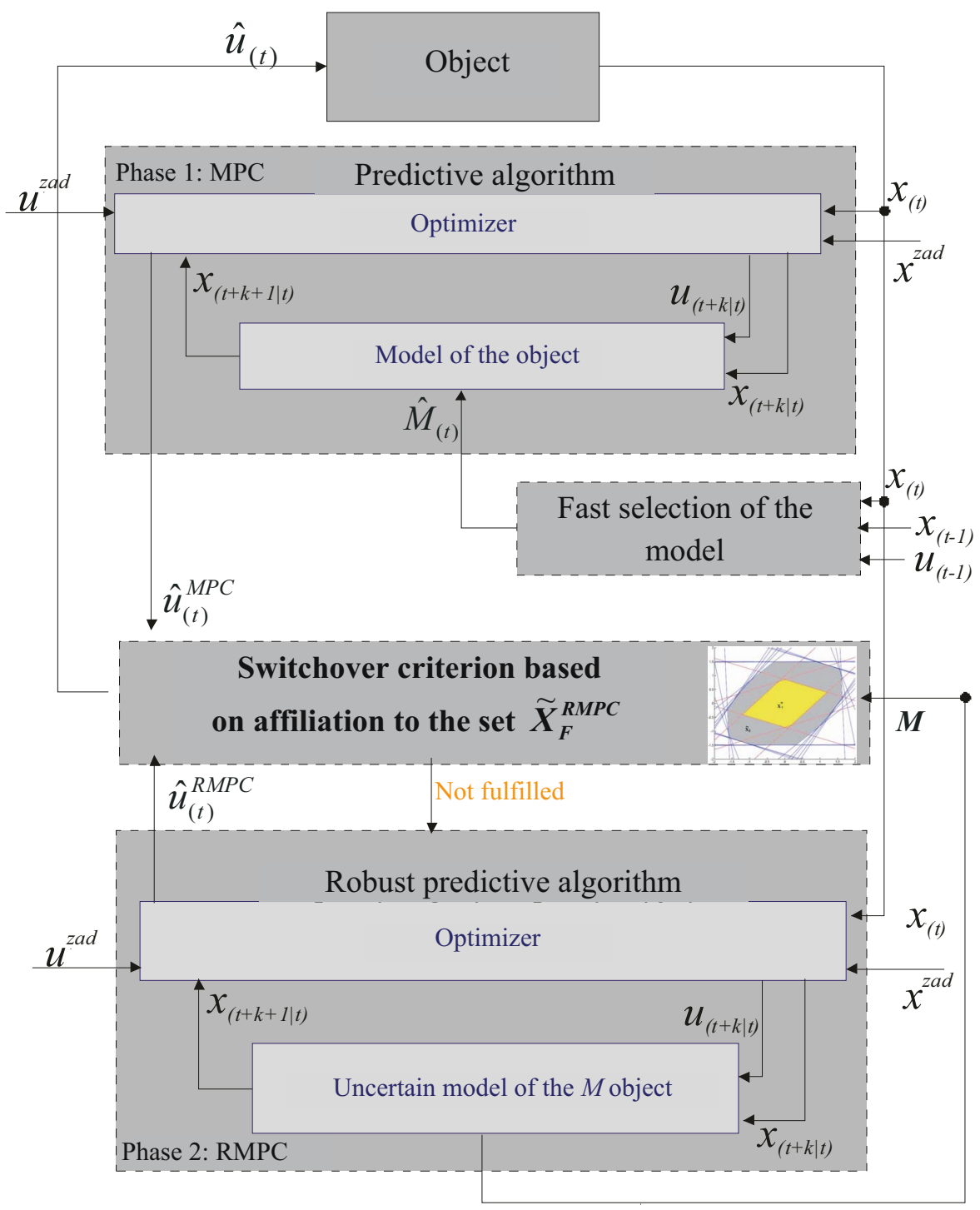

Fig. 11. The predictive algorithm RDP-MPC-MS 


\section{Example 5}

When the RDP-MPC-MS algorithm was being developed, the control task was considered which was intended to bring the status of an uncertain object to the working point $x_{w}=0$ under the constraints $\left\|x_{(t)}\right\|_{\infty} \leq 10,\left|u_{(t)}\right| \leq 1$. It was assumed that the accurate model $M^{3}$ (11.4) of the object remains unknown during the development phase and the model of uncertainty is defined by the relationship (19). The newly developed algorithm has the following parameters: $Q_{1}=Q_{2}=\operatorname{diag}\{1,1\}, R_{1}=R_{2}=[0,01], N_{l}=3, N_{2}=4, K_{T}(11.35), \boldsymbol{X}_{T}^{w}$ (35). For these parameters the set $\widetilde{X}_{F}^{R M P C}=\widetilde{X}_{F}$ adopts the form (36).

$$
\begin{gathered}
\boldsymbol{X}_{T}^{w}=\left\{x:\left[\begin{array}{cc}
1.593 & -1.0044 \\
-1.1593 & 1.0044 \\
0.4426 & 1.1638 \\
-0.4614 & 1.1638 \\
-0.4426 & -1.1638 \\
0.4614 & -1.1638
\end{array}\right] x \leq\left[\begin{array}{l}
1 \\
1 \\
1 \\
1 \\
1 \\
1
\end{array}\right]\right\}, \\
K_{T}=\left[\begin{array}{ll}
1.1593 & -1.0044
\end{array}\right]^{T} .
\end{gathered}
$$




$$
\left.\tilde{\boldsymbol{X}}_{F}=\left\{\begin{array}{cc}
-29.7287 & -81.0098 \\
-0.0330 & -6.9624 \\
-12.1973 & -0.4247 \\
-8.3407 & -1.3134 \\
-29.7511 & -68.9926 \\
-2.4244 & -0.7524 \\
-32.4665 & -82.8062 \\
-4.5214 & 2.4168 \\
-34.9059 & 34.6990 \\
-26.1757 & 19.7177 \\
-4.2243 & 2.8109 \\
-4.5214 & 2.6469 \\
-0.0388 & 4.5775 \\
29.7511 & 68.9926 \\
29.7287 & 81.0098 \\
32.4665 & 82.8062 \\
0.0330 & 6.9624 \\
-0.0170 & 4.5775 \\
26.1757 & -19.7177 \\
4.2243 & -2.8109 \\
34.9059 & -34.6990 \\
0.0388 & -4.5775 \\
12.1973 & 0.4247 \\
4.5214 & -2.4168 \\
8.3407 & 1.3134 \\
2.4244 & 0.7524 \\
4.5214 & -2.6469 \\
0.0170 & -4.5775
\end{array}\right] x \leq\left[\begin{array}{c}
147.4533 \\
10.4026 \\
20.0175 \\
14.6962 \\
130.9003 \\
4.6757 \\
153.1544 \\
6.8517 \\
62.7018 \\
41.7508 \\
6.4497 \\
6.8517 \\
6.8320 \\
130.9003 \\
147.4533 \\
153.1544 \\
10.4026 \\
6.8320 \\
41.7508 \\
6.4497 \\
62.7018 \\
6.8320 \\
20.0175 \\
6.8517 \\
14.6962 \\
4.6757 \\
6.8517 \\
6.8320
\end{array}\right]\right\}
$$

It was also assumed that the control system is operated under conditions of uncertainty, just the same as in Example 3 and defined in Tables 2 and 3. For initial conditions of the status variables $x_{(0)}=\left[\begin{array}{ll}1 & 0\end{array}\right]^{\mathrm{T}}$ and the initial model of the control $M_{(0)}=M^{4}(11.19)$ the timings for status variables, the control function and phase pointer of the RDP-MPC-MS algorithms are shown in Fig.12. Predictive structures with switchover functionalities offer huge opportunities to combine various approaches to predictive control in such a way that the algorithm with superior properties of its componential parts is finally achieved but disadvantages of its components can be avoided. In the case of the examined RDP-MPC-MS algorithm the high operation rate of the MPC-MS approach was combined with robust properties of the RMPC algorithm with min-max optimization. 

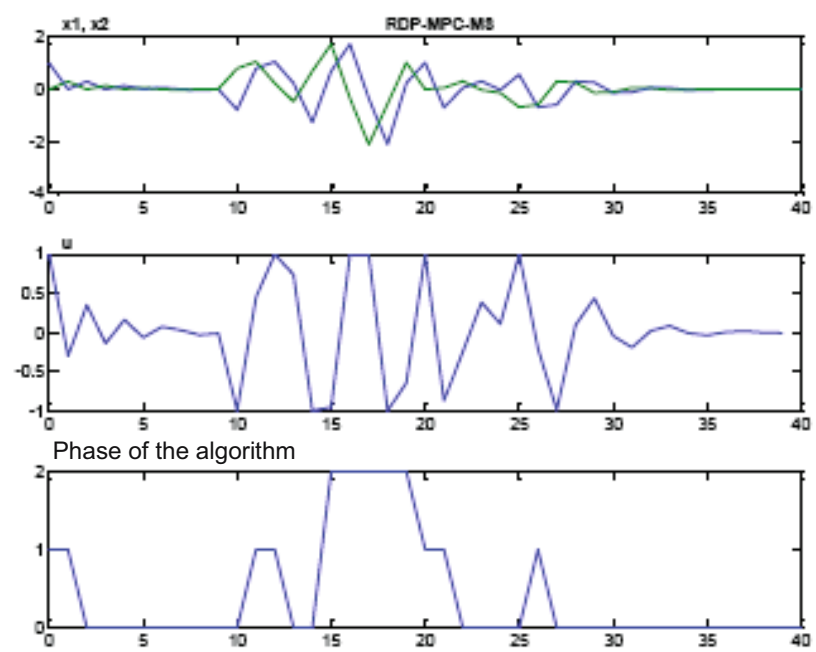

Fig. 12. The RDP-MPC-MS algorithm for the case when switchovers within the controlled object take place in accordance with the Table 2 under disturbances specified in Table 3. The timings respectively from top to bottom present status variables $x_{1(t)}, x_{2(t)}$, the control signal $u_{(t)}$ and the phase pointer of the algorithm: 2 - control function calculated by means of the algorithm for the second phase,

1 - control function calculated by means of the algorithm for the first phase, 0 - status within the set $\boldsymbol{X}_{\boldsymbol{T}}$.

In order to justify robust permissibility of the DPVSC-type algorithm one can use the theory that refers to robust permissibility of the second phase. For the considered RDP-MPC-MS algorithm it is the theory of invariant sets as well as the RMPC algorithm. The appropriately selected switchover criterion makes it possible to guarantee that the fast algorithm for the first phase (here the MPC-MS algorithm) is safe to the conditions of robust mpc-permissibility of the RMPC algorithm. If the initial status of the controlled object belongs to the set of mpc-permissible statuses $\widetilde{X}_{F}^{\text {RMPC }}$, then the robust mpc-permissibility is guaranteed by the conservative RMPC algorithm and the MPC-MS algorithm is intended to improve the quality of control. These effects have been achieved by the incorporation of the uncertainty model into the development process of these algorithms.

\section{d. Résumé}

Robust properties of predictive algorithms are the features that make the algorithms less sensitive to uncertainty circumstances. However, it is commonly known that the analysis of the conventional predictive approach in terms of its insensitivity is really difficult and needs strong and daring presumptions that impose constraints to generality of the deliberations. It is why this study proposes to take account for the uncertainty as early as during the development phase of the control system. 
The characteristic property that differ the proposed algorithms from other robust predictive approaches is fast selection of the model. This technique consists in the selection of the appropriate model for the control process from the predefined set of models where the selection is carried out on the basis of on-line measurements. It is also the approach that is different from the conventional adaptive rules as the precondition of continuous excitation applied to the controlled process becomes less crucial.

In the case of predictive algorithms where the conditions intended to guarantee robust properties of the algorithms are embedded into constraints of the optimization task, the robust permissibility is the factor of decisive importance, in particular when the controlled process is subject to physical limitations of the control signal or limitations of the controlled parameters.

The algorithms that base on the sector control are appreciated to their robust properties (insensitivity). But when the model that is used for the development significantly differs from the real object under control the insensitivity of DVSC algorithm is paid off by high variability of the control signal, which considerably decreases the quality of control and may prove inadmissible due to the already imposed constraints.

The application of the idea that takes advantage of the dynamic sector results in the fact that the switchover sector is developed on the model that better corresponds to the controlled process and under the assumption that the uncertainty is constant or it varies at slow rates. It is why the algorithm is developed on the basis of a more accurate model for the controlled object and consequently it demonstrated better quality of control and higher insensitivity to disturbances, even at presence of constraints.

When robust permissibility of the algorithm is hard to be achieved, the predictive toggled structures are worth consideration. It is the approach that uses two control algorithms instead of a single one, where at least one algorithm is a predictive one, where toggling between these two algorithms is carried out in an appropriate manner.

Every toggled structure should be furnished with the switchover criterion but it is not mandatory to define a priori the algorithms that are to be toggled between. This is why the toggled structure can be considered as the meta-algorithm, a frame to develop specific implementations of the algorithms.

The implementation of such a meta-algorithm not only consists in tuning of its parameters but above all in selecting the mutually toggled componential algorithms. This study presents two meta-algorithms of that type. For the first one the commutations take place at boundaries of the sector area and it is the toggled structure of the RMPC-SS-MS type. The second metaalgorithm assumes the occurrence of so called critical conditions that 
enforce switchovers between the two phases of the algorithm - it is the toggled structure of the RDP-MPC-MS type.

As the new idea of the dynamic sector is incorporated into the algorithm with sector-based control, the proposed method enables on-line tuning of the algorithm parameters so as to obtain a control system with higher insensitivity and better quality of control, even under constrained circumstances. Moreover, the application of a simple predictive algorithm (the first phase) for the two-phase algorithm has enabled the improvement of the control quality.

The approach that benefits from the sector of switchovers and the two-phase approach present the alternative method anabling to avoid an empty set of permissible solutions. As predictive algorithms are combined with the ones that use the dynamic switching sector, under circumstances when the optimization procedure of the predictive algorithm fails to find out a permissible solution, the sector-based control is launched where computations are performed regardless of constraints. In the case of the twophase algorithm the high operation rate of the MPC-MS approach was combined with robust properties of the RMPC algorithm with min-max optimization. In order to justify robust permissibility of the two-phase algorithm one can use the theory that refers to its robust component. For the considered RDP-MPC-MS algorithm it is the theory of invariant sets as well as the RMPC algorithm with the min-max optimization.

\section{References}

[1] Kothare M.V., Venkataramanan V. and Morari M.: Robust constrained model predictive control using linear matrix inequalities. Automatica, vol. 32, pp. 1361-1379, 1996.

[2] Sztyber K.: Odporne algorytmy regulacji predykcyjnej w warunkach niepewności modelu (Robust algorithms for predictive control under circumstances of the model uncertainty). Rozprawa doktorska, Wydział Elektroniki i Technik Informacyjnych Politechniki Warszawskiej, Warszawa 2008 (PhD Thesis, Faculty of Electronics and Information Technology of the Warsaw University of Technology, Warsaw 2008).

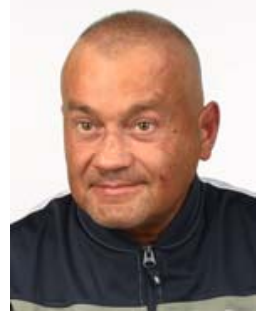

Krzysztof SZTYBER, PhD Eng. - instructor at the Air Force Institute of Technology, Division for Avionics, holds position of a computer engineer. He is interested in pure and applied mathematics, computer theory and practice; and also, in relationships between the mathematics and the information and computer sciences, e.g. numerical methods. 